\title{
Licorice and its applications for SARS-CoV-2
}

\author{
Siukan Law \\ Independent researcher, Hong Kong, China
}

\begin{abstract}
Licorice is a common Chinese herbal medicine in China. Glycyrrhizic acid $\left(\mathrm{C}_{42} \mathrm{H}_{62} \mathrm{O}_{16}\right)$, and glucoside are the major active chemical ingredients that possess antioxidant, antiviral, anti-infective, and anti-inflammatory properties. It can either cure (e.g. SARS-CoV-2) or cause diseases (e.g. hypertension or heart attack), so care is needed in the dosage of licorice. Some library search engines were used such as SCI/SCIE, PubMed, and Scopus. In this mini-review, the keywords searched include "licorice", "traditional Chinese medicine + licorice", "SARS-CoV-2", "licorice + SARSCoV-2" etc. in the last thirty years. The author discusses the background, usage, risk of licorice, the research progress on its antiviral activity as well as some Traditional Chinese Medicine (TCM) formulations for the prevention and treatment of COVID- 19 .
\end{abstract}

\section{Introduction}

Licorice is a flowering plant and has been used as Chinese herbal medicine in China for a long time. It belongs to the family of Leguminosae, which is derived from Glycyrrhiza glabra. The major active chemical ingredients consist of glycyrrhizic acid $\left(\mathrm{C}_{42} \mathrm{H}_{62} \mathrm{O}_{16}\right)$, and glucoside (Figure 1). Growing evidence has shown that the root of licorice presents different properties, such as antioxidant, antiviral, anti-infective, and anti-inflammatory properties. According to the Traditional Chinese Medicine (TCM) theory, licorice has the function to tonify and nourish the "qi", invig-

Correspondence: Siukan Law, E-mail: siukanlaw@hotmail.com

Key words: Licorice; Chinese herbal medicine; antiviral; SARS-CoV-2.

Conflict of interest: The author has no conflict of interest to disclose.

Availability of data and materials: All data generated or analyzed during this study are included in this published article.

Ethics approval and consent to participate: Not applicable.

Informed consent: Not applicable.

Received for publication: 14 December 2021

Accepted for publication: 30 December 2021.

This work is licensed under a Creative Commons Attribution NonCommercial 4.0 License (CC BY-NC 4.0).

CCopyright: the Author(s),2022

Licensee PAGEPress, Italy

Infectious Diseases and Herbal Medicine 2022; 3:184

doi:10.4081/idhm.2022.184 orate the spleen and harmonize the stomach, clear heat, detoxify, reduce phlegm, relieve cough, and alleviate pain. ${ }^{1}$ It also helps to moderate other herbs in the TCM formulation.

\section{Risk of Licorice}

Licorice is also used as a flavoring in candies called "Black licorice". However, excess consumption of glycyrrhizic may result in adverse effects, e.g. hypertension crisis, muscle breakdown, and heart disease. The safety level of glycyrrhizin is considered as 0.2 $\mathrm{mg} / \mathrm{kg} /$ day. ${ }^{2}$

Ottenbacher et al. identified large quantities of glycyrrhizic acid-induced hypertension. Glycyrrhizic acid affects the level of sodium and potassium causing edema, hypokalemia, metabolic alkalosis, and low plasma renin activity. The type 2 isoenzyme of $11 \beta$-hydroxysteroid dehydrogenases (11 $\beta$-HSD) is suppressed leading to cortisol inactivation and mineralocorticoid excess (AME) in the renal collecting tubules. ${ }^{3}$ Deutch et al. explained the tribasic glycyrrhizin might have existed in calcium and potassium

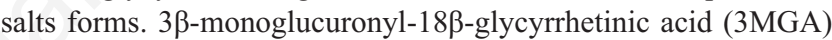
and an aglycone 18ß-glycyrrhetinic acid are hydrolyzed from glycyrrhizin after oral ingestion. This promoted potassium levels in the body to fall, causing abnormal heart rhythms and congestive heart failure. ${ }^{4}$ Srivatsa et al. discovered the active component of glycyrrhizin as a thrombin inhibitor and metabolized warfarin through the suppression of a P450 system. Its prolonged fibrinogen clotting times, the anti-thrombotic activity influenced the function of blood anti-coagulation either in cardiovascular or renal systems. ${ }^{5}$

\section{Case study of licorice}

On the $24^{\text {th }}$ of September in 2020, a 54-year-old man died who ate several packages of licorice-flavored candy daily. The glycyrrhizic acid of black licorice resulted in uncontrolled cortisol levels and caused some diseases such as hypertension, hypokalemia, metabolic alkalosis, fatal arrhythmias, and renal failure. ${ }^{6}$ Given this phenomenon, the Food and Drug Administration (FDA) issued in early 2017 who are 40 years of age or above cannot intake a maximum of two ounces per day of black licorice, otherwise, it may risk of irregular heart rhythm or arrhythmia. ${ }^{7}$

\section{Research progress of licorice on antiviral activity}

Glycyrrhizic acid is one of the bioactive components in licorice that possess an antiviral function. In early 1979, Pompei et al. reported glycyrrhizic acid could suppress the growth and cytopathology of four viruses including vaccinia, herpes simplex, newcastle disease, and vesicular stomatitis. ${ }^{8}$ Badam et al. discovered the concentration of licorice and ammonium salt of glycyrrhizic acid are only required 1000 micrograms $/ \mathrm{mL}$ which inhib- 
ited the formation of plaque in the Japanese Encephalitis Virus (JEV). This was non-toxic to the kidney. ${ }^{9}$ Lin et al. also identified glycyrrhizic acid could inhibit the infection of Epstein-Barr Virus (EBV) by interfering with its virus self-replication cycle in the early stage. The concentration of glycyrrhizic acid was 7.5 times more active against EBV. It was increasing the cytotoxicity of EBV resulting in an enhanced therapeutic index. ${ }^{10}$ Another research from Bentz et al. found that glycyrrhizic acid was not affected inducing reactivation of the virus, but it could reduce the ability of a virus self-replication to infect additional cells for the treatment of EBV-associated lymphoid malignancies. ${ }^{11}$ Ashfaq et al. reported glycyrrhizic inhibited Hepatitis C Virus (HCV) and $\mathrm{HCV}$ core gene expression or function in a dose-dependent manner causing synergistic effect with interferon. ${ }^{12}$ Michaelis et al. reported glycyrrhizin suppresses with $\mathrm{H} 5 \mathrm{~N} 1$ replication and H5N1induced pro-inflammatory gene expression. It inhibited the formation of Reactive Oxygen Species (ROS) in H5N1 and reduced the activation of $\mathrm{NF \kappa B}, \mathrm{JNK}$, and p38 to interference with the influenza A virus replication. ${ }^{13}$

\section{SARS-CoV-2}

SARS-CoV-2 is a beta-coronavirus with $79 \%$ genome sequence identity with SARS-CoV and 50\% with MERS-CoV. ${ }^{14}$ This enters into the host cell by fusion and envelope with the cell membrane or membrane fusion within the endosome after endocytosis. The virus is activated by binding the Receptor-Binding Domain (RBD) of the $\mathrm{S}$ protein to an Angiotensin-Converting Enzyme 2 (ACE2) receptor at the cell surface causing the infection of the respiratory tract and lung. ${ }^{15}$

\section{Licorice inhibits SARS-CoV-2 activity}

Van de Sand et al. identified glycyrrhizin prevents the SARSCoV-2 spike protein replication as its inhibiting the SARS-CoV-2 main protease Mro. Transmembrane Serine Protease (TMPRSS2) is effective to block the entry of its virus invade. The glycyrrhizin in licorice is a neutral inhibitor for the SARS-CoV-2 main protease. ${ }^{16}$ Murck et al. discovered the effect of glycyrrhizic acid on a SARS-CoV-2 transmission, which involved the expression of type 2 Transmembrane Serine Protease (TMPRSS2) to reduce its uptake. Glycyrrhizin could reduce the severity of infection with COVID-19 include blocking the number of active sites and providing an ACE2 independent anti-inflammatory mechanism. ${ }^{17}$
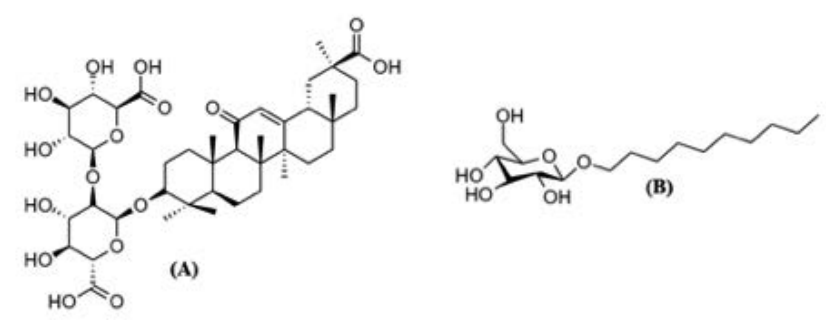

Figure 1. Chemical structure of $(A)$ glycyrrhizic acid $\left(\mathrm{C}_{42} \mathrm{H}_{62} \mathrm{O}_{16}\right)$ and (B) glucoside.

\section{TCM formulations of Licorice for SARS-CoV-2}

Licorice is a guiding drug in some TCM formulations for the treatment and prevention of SARS-CoV-2 including Qingfei paidu decoction, Qingfei toxie fuzheng decoction, and Gan cao gan jiang decoction. These treatments and preventions are the functions to store, regulate vital $q i$ for strengthening an immune system in the lung and spleen to fight against SARS-CoV-2. ${ }^{18}$

\section{Conclusion}

All of the above information demonstrates that licorice has many pharmacological properties but it must pay attention to the "dosage", especially black licorice in western countries as a consumer product. Its active ingredient of glycyrrhizic acid either cure (e.g. SARS-CoV-2) or cause diseases (e.g. hypertension or heart attack).

\section{References}

1. Wang D, Liang J, Zhang J, et al. Natural chalcones in Chinese materia medica: Licorice. Evid Based Complement Alternat Med 2020;2020:3821248.

2. Aoki F, Nakagawa K, Kitano M, et al. Clinical safety of licorice flavonoid oil (LFO) and pharmacokinetics of glabridin in healthy humans. J Am Coll Nutr 2007;26:209-18.

3. Ottenbacher R, Blehm J. An unusual case of licorice-induced hypertensive crisis. S D Med 2015;68:346-9.

4. Deutch MR, Grimm D, Wehland M, et al. Bioactive candy: Effects of licorice on the cardiovascular system. Foods 2019;8:495.

5. Srivatsa A, Liu J, McFarland J, Kaul V. Does eating black licorice mimic melena or cause it? Am J Gastroenterol 2008;103:S277-8.

6. Omar HR, Komarova I, El-Ghonemi M, Fathy A, Rashad R, Abdelmalak HD, Yerramadha MR, Ali Y, Helal E, Camporesi EM. Licorice abuse: time to send a warning message. Ther Adv Endocrinol Metab 2012;3:125-38.

7. Murphy S, Agger S, Rainey P. Too much of a good thing: a woman with hypertension and hypokalemia. Clin Chem 2009;55:2093-96.

8. Pompei R, Flore O, Marcialis MA, et al. Glycyrrhizic acid inhibits virus growth and inactivates virus particles. Nature 1979;281:689-90.

9. Badam L. In vitro antiviral activity of indigenous glycyrrhizin, licorice and glycyrrhizic acid (Sigma) on Japanese encephalitis virus. J Commun Dis 1997;29:91-9.

10. Lin JC, Cherng JM, Hung MS, et al. Inhibitory effects of some derivatives of glycyrrhizic acid against Epstein-Barr virus infection: Structure-activity relationships. Antiviral Res 2008;79:6-11.

11. Bentz GL, Lowrey AJ, Horne DC, et al. Using glycyrrhizic acid to target sumoylation processes during Epstein-Barr virus latency. PLoS One 2019;14:e0217578.

12. Ashfaq UA, Masoud MS, Nawaz Z, Sheikh R. Glycyrrhizin as antiviral agent against Hepatitis C Virus. J Transl Med 2011;9:112.

13. Michaelis M, Geiler J, Naczk P, et al. Glycyrrhizin exerts antioxidative effects in $\mathrm{H} 5 \mathrm{~N} 1$ influenza A virus-infected cells and inhibits virus replication and pro-inflammatory gene 
expression. PLoS One 2011;6:e19705.

14. Hu B, Guo H, Zhou P, Shi ZL. Characteristics of SARS-CoV2 and COVID-19. Nat Rev Microbiol 2021;19:141-54.

15. Zhang Q, Xiang R, Huo S, et al. Molecular mechanism of interaction between SARS-CoV-2 and host cells and interventional therapy. Sig Transduct Target Ther 2021;6:233.

16. Van de Sand L, Bormann M, Alt M, et al. Glycyrrhizin effectively inhibits SARS-CoV-2 replication by inhibiting the viral main protease. Viruses 2021;13:609.

17. Murck H. Symptomatic protective action of glycyrrhizin (licorice) in COVID-19 infection? Front Immunol 2020;11: 1239.

18. Law S, Xu C, Leung AW. Use of Chinese medicine in the prevention and treatment of COVID-19 in China and Asia. Asian Educ Dev Stud 2020;10:198-209. 